\title{
चंबा की पंगवाल जनजाति में प्रयुक्त पौराणिक लोकगाथाओं का सांस्कृतिक अवलोकन शंकरलाल
}

Ph.D. Research Scholar, Department of Music, Panjab University, Chandigarh

जनजातीय क्षेत्र पांगी हिमाचल प्रदेश के चंबा जिले की एक प्राकृतिक सुषमा संपन्न तहसील है जो चंद्रभागा नदी के दोनों और बसा क्षेत्र है। यहां पर स्थानीय भाषा पंगवाली का इस्तेमाल किया जाता है और इस क्षेत्र को पैगेई,पंगति तथा पांगी के नाम से जाना जाता है।9 यहां पर बसने वाले लोगों को पंगवाल नाम की संज्ञा दी जाती है। इस पांगी घाटी का मुख्यालय किलाड़ में स्थित है। विकट भौगोलिक परिस्थिति के कारण संपूर्ण घाटी वर्ष में लगभग छ: महीने बंद रहने के कारण किसी का भी ध्यान यहां की सांस्कृतिक गतिविधि व सांगीतिक धरोहर की ओर नहीं गया। यहां पर हिंदू और बौद्ध धर्म के अनुयाई रहते हैं १६ पंचायतों के अंतर्गत यहां की कुल आबादी लगभग बाईस हज़ार के करीब है। यहां पर प्रसिद्ध मिंधल माता का मंदिर भी स्थित है जहां पर खेतों में हल जोतने के लिए एक ही बैल का सहारा लिया जाता है। यहां के लोग धार्मिक स्वभाव के होते हैं और देवी-देवताओं पर अटूट श्रद्धा रखते हैं। यहां की अपनी लोक मान्यताएं आस्था और विश्वास परंपराएं आदि हैं, जिन की झलक यहां के धार्मिक लोकाचारों, रस्मों, रीति-रिवाजों व अन्य सांस्कृतिक गतिविधियों में मिलती है।

लोक से अभिप्राय उस जनसमूह से है जो नगर, कख्बा, गांव, पहाड़, समतल कहीं भी अपनी परंपरा और पद्धति में जीता है। वह स्वयं से अबोध और सहज जीवन जीता हुआ हर स्थान पर हर युग में जीवंत चेतनशील और कार्यशील रहता है।२ लोकगाथा लोक जीवन की अभिव्यक्ति है।और इसका इतिहास भी उतना ही पुराना है जितना मानव उद्भव का। सबसे पहले गाथा शब्द का प्रयोग ऋग्वेद में पाया जाता है (ऋ. -३२-9) वैदिक काल में यज्ञ के अवसर पर गाथा गाने की प्रथा थी इन्हें गाने वालों को गाथिन कहा जाता था। जातको में श्लोकबध्द रचना को गाथा का नाम दिया जाता है। प्राकृतिक भाषा में लिखी गई गाथा सप्तशती प्रसिद्ध रचना है। भोजपुरी में गाथा का अर्थ कथा है। लोकगाथाओं के लिए अंग्रेजी में बैलेड शब्द प्रचलित है बैलेड शब्द लैटिन भाषा के बेलारे शब्द से निकलता है। बेलारे का अर्थ है नृत्य करना। संभवतः यह कहा जा सकता है कि प्रारंभ में नृत्य के सहयोग से गाए जाने वाले गीत को बैलेड कहा जाता है लेकिन वर्तमान समय में अर्थात्मक गीतों को ही बैलेड कहा जाता है।

आदि काल में मानव समाज जब आनंद मस्त होकर गाते और मनोरंजन करते थे तो उनके गीत और गाथा मौखिक ही होते थे क्योंकि उस वक्त समाज में लिपि का प्रचार नहीं हुआ था, यही कारण है कि संसार की तमाम लोकगाथाओं की मुख्य विशेषता एक ही रहती है जैसे- रचयिता का अज्ञात होना, मूल पाठ का अभाव, स्थानीयता का पुट, सिर्फ मौखिक परंपरा, टैकपदों की पुनरावृति आदि। लोकगाथाओं की परंपरा सदा से ही मौखिक रही है अतःयह संभव है कि गाथाओं के लेखक का नाम लुप्त हो गया हो।५ भिन्न-भिन्न व्यक्ति या लोगों द्वारा गाए जाने पर इसमें परिवर्तन एवं परिवर्धन होता रहता है। इन घटनाओं में मूल लेखक का व्यक्तित्व नष्ट एवं तिरोहित हो जाता है, और यह गाथाएं जनसामान्य की संपत्ति बन जाती हैं।६ लोक का अस्तित्व प्राचीनकालीन सर्वव्यापक, सनातन, सहज, सरल, स्वाभाविक, सात्विक, निरंतर, कालातीत और सर्वज्ञ है। पीढ़ी दर पीढ़ी युग दर युग प्रवहमान समय के पद चिन्हों 
के अनुरूप मानव की मूल संवेदनाओं को अतीत और वर्तमान में शब्द, लय, ताल देती लोकगाथाओं की परंपरा मौखिक रूप से सहजता के साथ पांगी जनजातीय लोक समाज का सदियों से दिग्दर्शन करती आ रही हैं।

जनजातीय क्षेत्र पांगी की पंगवाल संस्कृति व लोकाचार में लोकगाथा नाम कुछ अलग सा और नूतन प्रतीत होता है। पंगवाली बोली में लोकगाथाओं को घुरेई नाम से जाना जाता है। घुरेई अक्सर त्योहारों मेंलो व उत्सवों के शुभ अवसर पर प्रस्तुत की जाती हैं, जिसमें संपूर्ण पांगी घाटी में बसने वाली भोली-भाली जनमानस की समग्र लोक सांस्कृतिक गतिविधियों की झलक स्पष्ट दिखाई देती है। यह लोकगाथाऐं विशेषतया स्त्रियों द्वारा सामूहिक नृत्य प्रस्तुत करते हुए गाई जाती हैं। इस प्रकार पांगी क्षेत्र में अनेक प्रकार की लोक गाथाएं हैं जो यहां के सामान्य जनजीवन का एक हिस्सा है तथा यहां की लोक संस्कृति का प्रमुख अंग भी है।

पंगवाली घुरेई आकार में अनावश्यक रूप से अधिक लंबी नहीं होती है परंतु प्रबंधात्मकता का पुट आरंभ से अंत तक सदैव विद्यमान रहता है। यहां के लोक कलाकार परंपरागत ढंग से अपनी अपनी सामर्थ्य के अनुसार तन्मयता से किसी भी पौराणिक व ऐतिहासिक विशिष्ट पात्रों की महिमा का बखान घुरेई के अंतर्गत बड़े ही सुंदर ढंग से करते हैं। हालांकि कभी-कभी मनोरंजन हेतु मेलों और त्यौहारों के अतिरिक्त विवाह व अन्य रस्मों में भी घुरेई गाई जाती हैं।

पंगवाली लोक संस्कृति में दृष्टिपात करने से यह ज्ञात होता है कि इस क्षेत्र विशेष में जनमानस धार्मिक भावना के अनुसार अपने- अपने इष्ट देव के प्रति अटूट श्रद्धा, धर्म-अधर्म तथा पाप-पुण्य आदि पर अत्यधिक विश्वास करता है। इस प्रकार से पौराणिक एवं धार्मिक लोगाथाओं का प्रचलन पंगवाल जनजाति व संस्कृति में सर्वाधिक होता है। पौराणिक चरित्रों से सम्बंधित कथा को पौराणिक गाथा कहा जाता है तथा धार्मिक भावना को अभिव्यक्त करने वाली गाथा को धार्मिक गाथा कहा जाता है। पंगवाली लोक साहित्य में महाभारत एवं पुराणों के कथानकों पर आधारित अनेकोनेक लोकगाथाऐं प्राप्त होती हैं। इन लोकगाथाओं की प्रमुख विशेषता यह है कि इसमें लोक कलाकार व कवि ने अपनी धारणा व सामर्थ्य के अनुसार आख्यान बनाया होता है, जो कभी-कभी जनपदीय धारणाओं के ठीक विपरीत भी हो सकता है। इस प्रकार की लोकगाथा में मुख्यतः किसी प्रख्यात चरित्र की महिमा का बखान किया जाता है किंतु परंपरागत एवं मौखिक होने के कारण इस में प्रक्षिप्त अंश भी प्रचुर मात्रा में जुड़ जाते हैं। हिमाचल के सभी भूखंडों, समुदाय विशेष और वर्ग विशेष में ऐसी आख्यानक कथाएं पद्य रूप में परंपरित हैं। इन्हें शिवीणी,रमीणी, पंडवीणी, पवाड़े,वारे आदि के रूप में जानते हैं। हर जनपद का लोक इन्हें परंपरा में संभाले हैं।

इन पंगवाली पौराणिक एवं धार्मिक लोकगाथाओं की सरसता अद्वितीय है तथा कल्पना का कौशल भी अति प्रशंसनीय एवं दर्शनीय है। भगवान शिव शंकर, विष्णु, गंगा, पार्वती, राहु, केतु चाँद, सूरज राहुकेतु, ग्रह तथा नक्षत्र आदि से संबंधित अनेक लोक गाथाएं पंगवाल समाज में प्रचलित हैं। जिसमें से वार पूजन के अवसर पर गाए जाने वाली पौराणिक लोकगाथा में भगवान शिव और गोरा के विवाह संबंधी वर्णन तथा भगवान विष्णु संबंधी लोकगाथा का वर्णन इस प्रकार से-

माघे रे चौ पांज़ शिवा गोरी रे ब्याह वै लागे।

ब्रह्मा विष्णु वो शिवा गौरी रे ब्याह वै चले। 
तारा मंडला वो शिवा गोरी रे ब्याह वै चले। नौलख जानी वो शिवा गोरी रे ब्याह वै चले। नौ लाख तारे वो शिवा गौरी रे ब्याह वै चले। चांदरो- सूरज़ वो शिवा गोरी रे ब्याह वै चले। चिड़िया पखेरू वो शिवा गोरी रे ब्याह वै चले। दाता विधाता वो शिवा गोरी रे ब्याह वै चले। सुथण्यला भोट वो शिवा गोरी रे ब्याह वै चले। ताई और पाठ वो शिवा गोरी रे ब्याह वै चले। माघे र चौ पांज़ शिवा गोरी रे ब्याह वै लागे।

उपर्युक्त लोकगाथा में भगवान शिव और माता पार्वती के शुभ विवाह संबंधी वर्णन मिलता है। इस गीत के बोलों व पंक्तियों में विवाह संबंधी वर्णन मिलने से ऐसा प्रतीत होता है कि इस जनजातीय क्षेत्र पांगी के विवाह संस्कारों में इस लोक गीत का गायन किया जाता होगा किंतु ऐसा नहीं है बल्कि इस गाथा को माघ के महीने में नवग्रह पूजन अर्थात वारयात के शुभ अवसर पर मुख्यतः ब्राह्मणों द्वारा नवग्रह शांति हेतु गाया जाता है। स्थानीय लोगों की मान्यता अनुसार इस माघ के महीने में पांगी घाटी के विवाह संस्कारों को वर्जित माना जाता है, और नराउड़ नामक समयावधि जो कि माघ महीने के प्रथम से शुरू होता है जो $9 ५$ तारीख तक रहता है। इस महीने का नाम तक लेना पंगवाल समाज में वर्जित है। इस माह में केवल सर्व शक्तिमान भगवान शिव और मां पार्वती का ही शुभ विवाह हुआ है शायद यही वजह रही होगी कि यहां विवाह संस्कार के लिए विशेष समय निर्धारित किया जाता है।

लोकगाथा की पंक्तियों के अनुसार माघ के चार पांच तारीख को भगवान शिव और गौरी का विवाह चल रहा है, जिसमें ब्रह्मा और विष्णु समेत समस्त तारामंडल चांद -सूरज नौ लख तारे पशु- पक्षी, दाताविधाता, नौ लाख प्राणी आदि भगवान शिव व गौरी के विवाह में अपनी उपस्थिति दर्ज करवाते हैं। इन सबके अतिरिक्त ताई और पठ जो कि घराट के दोनों बड़े बड़े वृत्ताकार पत्थर होते हैं) और सूथण पहने भोट भी विवाह में शरीक होते हैं। इन सभी बातों को ध्यान में रखकर पंगवाल समाज में विवाह संस्कार पूर्ण किए जाते हैं। इसी तरह की एक और लोकगाथा भी प्रस्तुत है जिसमें भगवान विष्णु व उनके पुत्र पुत्रियों संबंधित विशिष्ट पात्रों का वर्णन मिलता है जो इस प्रकार से है।

$$
\begin{aligned}
& \text { बिष्णुएरी घरै वो चार धीया जमिऐ ओ। } \\
& \text { चार जमें धीया वो दुई जमें लाल हो।। } \\
& \text { बाबा विष्णु वो पंडित सदाय हो.. } \\
& \text { पंडित सदाय वो पतरी बनाए हो.. } \\
& \text { जेठी धिया नाम गोरा राणी रखीऐ हो.. } \\
& \text { तैस कैंई केंठुडुआ वो जुनी भराड़ी हो.. } \\
& \text { पुत्रेरि नामें बो चंदर त सूरज हो३ } \\
& \text { गंगा गौरा शिव जोगे ब्याही हो३ } \\
& \text { काली कस्तूरी कैण राजे ब्याही हो.. } \\
& \text { जुनी भराड़ी बो लछ़या- गोरु चारै हो.. }
\end{aligned}
$$


चंदरौ सूरज बो नीकुणु बालके हो.. धरती अंदरै बो अन्नै पैइये काड़ा हो. बाबा बिष्णु बो राहु केतु घारे हो३३३... अन्न दियाल बो कौल बचन हारै हो३३.

इससे आगे का संक्षिप्त वर्णन इस लोकगाथा के शुरुआत से लेकर हिंदी मे किया जा रहा है। इस लोक गाथा के अनुसार भगवान विष्णु के घर में चार पुत्रियां पार्वती, गंगा, काली एवं जुनी भराड़ी तथा दो पुत्रों सूरज और चंद्र के जन्म लेने की बात कही गई है। भगवान विष्णु सभी बच्चों के नामकरण जन्मपत्री पंडित से करवाता है। गंगा और गौरा का विवाह शिव के साथ हुआ। काली कस्तूरी का विवाह किसी राजा के साथ हुआ। छोटी बहन जुनी भराड़ी भेड़ और पशु चराती थी, जबकि छोटे भाई चांद और सूरज अभी बाल अवस्था में थे इस प्रकार से समय बीतता गया और पृथ्वी के ऊपर भयानक अकाल पड़ जाता है।

जगत के पालक भगवान विष्णु अनाज के प्रयोजन हेतु राहु केतु के घर जाते हैं। राहु केतु भगवान विष्णु से अनाज के बदले कौल वचन लेते हैं कौल वचन एक ऐसा वचन होता है कि जिसे हर संभव पूरा करना ही पड़ता है ऐसी पंगवाल लोगों की मान्यता है। भगवान विष्णु ऋण स्वरूप अनाज लेते हुए कौल वचन देते हैं। परिणाम स्वरूप भगवान विष्णु को अपनी छोटी लाडली पुत्री का विवाह सूद समेत ऋण ना चुका पाने के कारण राहु केतु से करवाना पड़ता है। इस प्रकार विष्णु भगवान को बहुत दुख होता है।इस घटना को कई वर्ष बीत गए और चंद्र और सूरज अब जवान हो गए थे लेकिन अपने पिता द्वारा राहु केतु का ऋण ना चुकाने संबंधित कष्टों से अनभिज्ञ थे। उधर विष्णु की बेटी जुनी भराड़ी को राहु केतु के घर पर कई यातनाएं सहनी पड़ रही थीं।

एक दिन संयोगवश घूमते फिरते चंद्र और सूरज दोनों भाई राहु केतु के पनिहार पनघट पर पहुंच गए वहां उन्होंने देखा कि एक सुंदर स्त्री तेल से सने हुए कपड़े धोते हुए रो रही थी। आँसू पोंछते हुए दोनों भाई हास परिहास करने लगे। जुनी भराड़ी ने अपनी सारी व्यथा सुनाई और मां बाप और भाई बहन आदि का वृत्तांत सुनाया, और कहा कि मेरे पिता ने मुझे कौल वचन द्वारा हारकर राहु केतु की पत्नी बना दिया है। यह सब सुनते ही दोनों भाई रोने लगे और कहा, "है! बहन हमें माफ करना।" जुनी मराठी को मालूम हुआ कि यह दोनों नवयुवक मेरे भाई चंद्र और सूरज हैं उन्हें गले लगा कर खूब रोती है। बहन की आपबीती पर दोनों भाइयों को दया आ जाती है और पूछते हैं कि राहु केतु कहां गए हैं,?इस समय जुनी भराड़ी बताती है कि दोनों 9 महीने के शिकार पर गए हैं। यह सुनकर मौका पाते ही दोनों भाई अपनी बहन को साथ ले जाने का निश्चय करते हैं, और चंद्र ने अपनी जांघ को चीरकर पठ में अपनी बहन को छुपा लिया और वापस चले गए।

शिकार से घर वापस लौटने पर जुनी भराड़ी के ना मिलने से राहु-केतु बहुत दुखी होते हैं, और अंत में पता चलता है कि उसे उसके दोनों भाई चांद और सूरज ले गए हैं तब राहु केतु भी चंद्र और सूर्य से लड़ने का निश्चय करते हैं।

जब-जब उन्हें जुनी भराड़ी का स्मरण होता है तब-तब वे सूरज और चांद को ग्रस्ते हैं।इसलिए सूर्य एवं चंद्र ग्रहण लगता है ऐसे यहां के लोगों की मान्यता है। जीवन के दुख भार को ढोने के लिए किस प्रकार की मान्यताएं इन पंगवाल जनों में मिलती हैं इनकी स्पष्ट झलक इन घुरेईयों में उपलब्ध होती 
हैं। इनका मानना है कि भगवान विष्णु को विभिन्न समस्याओं का सामना करते हुए लोकाचार निभाना पड़ा, हम तो मानव है हमारी तो औकात ही क्या है। इस प्रकार से यह लोकगाथा पंगवाल जन-जीवन से संबंधित धार्मिक विश्वास एवं मान्यताओं का सजीव चित्रण प्रस्तुत करती है।

जनजातीय क्षेत्र पांगी के लोक गाथाओं का विस्तृत एवं सूक्ष्म विश्लेषण करने से यह ज्ञात होता है कि पंगवाल लोकजीवन अनेकोनेक प्रकार के विषयों से संबंधित सांस्कृतिक यात्रा की युगीन प्रवृत्तियों का स्वाभाविक एवं यथार्थ परिचय तथा चित्रण करने में लोकगाथाओं घुरेईयों का विशेष महत्व व योगदान है। यहां की लोगाथाओं में सामान्य जनमानस में व्याप्त विश्वास, प्रेम, स्नेह, ममता, ईर्ष्या आदि की झलक दिखाई देती है। लोक कंठ में निवास करने वाली ये लोगाथाऐं पीढ़ी दर पीढ़ी एक दूसरे को प्राप्त होती आ रही है, इसलिए इनकी घटनाओं एवं चरित्र संबंधी पात्रों में भी हेरफेर होता रहा है, और इस प्रकार ऐतिहासिक पात्र एवं घटनाएं भी मूल रूप से कुछ सीमा तक अवश्य विकृत हो गई है। अतः इन लोगों के ऐतिहासिक प्रमाण संदिग्ध कहे जा सकते हैं। लोगों का मूल उद्देश्य नीति की शिक्षा तथा आचार भावना ना होकर वास्तव में विषय प्रधान काव्य हैं। भले ही मनोरंजन के साथ-साथ ही इनमें यदा-कदा कुछ ज्ञान का उपदेश भी निहित रहता है। यहां पर प्रयुक्त घुरेई इस क्षेत्र के लोकाचारों, लोक विध्वासों, मान्यताओं धारणाओं आदि के प्रति पूर्ण आस्था प्रदर्शित करती हैं, जिसके अध्ययन से पंगवाल समाज की संपूर्ण लोक संस्कृति का ज्ञान हो जाता है।अतः पंगवाल लोगों की पंगवाली भाषा व बोली में गाए जाने वाली यह पौराणिक लोकगाथाऐं घुरेई अनेक प्रकार के विषयों से संबंधित इस दुर्गम क्षेत्र की समग्र जानकारी उपलब्ध करवाती है जिनका संरक्षण व संवर्धन के लिए आवश्यक व सार्थक कदम उठाने की अति आवश्यकता है।

\section{संदर्भ}

9 अमर सिंह रणपातिया, पांगी, एक बहुआयामी परिचय, हिमाचल अकादमी ऑफ आर्ट 2002

२ डॉ गौतम शर्मा व्यथित, सोमसी, संयुक्तांक, 98४9-४२,२०१९, पृष्ठ १६

३ बटुक नाथ शर्मा, पाली जातकाबली,पृष्ठ ₹

8 डॉ कृष्ण देव उपाध्याय, लोक साहित्य की भूमिका, पृष्ठ $₹ 4$

५. श्रीराम शर्मा, लोक साहित्य स्वरूप और मूल्यांकन, पृष्ठ 50, दक्षिण प्रकाशन, हैदराबाद, प्र.सं. 1986

६ श्रीराम शर्मा, लोक साहित्य स्वरूप और मूल्यांकन, पृष्ठ 50, दक्षिण प्रकाशन, हैदराबाद, प्र.सं.1986

$\vartheta$ डॉ गौतम शर्मा सोमसी पृष्ठ १६ 